\title{
HIV/Aids fear appeal advertisements directed at different market segments: Some considerations for corporate sponsors and NPO's
}

\author{
M. Terblanche-Smit* \\ University of Stellenbosch Business School, \\ P O Box 610, Bellville, 7535, Republic of South Africa \\ marlize.terblance-smit@usb.ac.za \\ N.S. Terblanche \\ Department of Business Management, Stellenbosch University, \\ Private Bag X1, Matieland 7602, Republic of South Africa \\ et3@sun.ac.za
}

\begin{abstract}
The purpose of social advertising is to influence human behaviour for societal benefit. Given concern about the Aids pandemic in South Africa, this study used structural equation modelling and partial least squares to investigate whether the use of fear in social advertising increases the likelihood of adopting appropriate behaviour pertaining to HIV/Aids prevention. Fear, attitude towards the advertisements, severity, susceptibility, response efficacy and self-efficacy were examined for their effect on behavioural intent of young adults within specific market segments. Relationships were found among susceptibility, fear, attitude, and behavioural intent, and different relationship paths were identified for segments based on gender and culture/racial groupings. These differences show the value in tailoring fear appeals to different segments when addressing social cause advertisements.
\end{abstract}

*To whom all correspondence should be addressed.

\section{Introduction}

The deaths of over 34 million people in the world due to Aids-related causes could have been prevented. Most of these deaths resulted from unsafe sexual behaviour. At the end of 2011 more than 34 million people in the world were living with HIV (World Health Organization, 2011). In South Africa 50 percent of HIV infections are transmitted before the age of 20, with more than 5.6 million HIV positive people in a country with 50 million people (Avert 2011, World Health Organisation, 2011). It is therefore clear to see how important it is to persuade young people that engaging in sexual activity, and the way they go about it, can be a matter of life or death. Persuading them to take measures to prevent getting or transmitting the virus is clearly a vital task of social marketing.

Yet not all young people are the same, so it seems that social marketing campaigns can be better tailored, to fit differing segments of this young-adult target market than is currently the case. Thus, it may increase the effectiveness and save many lives. Since this study was conducted in South Africa, it was assumed that different racial groups could react differently to social marketing campaigns, given historical differences where people were discriminated against because of race or cultural group. The present study applies knowledge of market segmentation to the young-adult segment of the population. This study investigates how fear appeals can influence attitude as an antecedent of behavioural intent, and ultimately behavioural change amongst young-adults. Threat appraisal, consisting of severity and susceptibility to the threat posed by HIV/Aids, as well as coping appraisal, consisting of response efficacy and self-efficacy, and the influence on attitude, were examined as antecedents to fear and attitude respectively. Ample evidence exists of the influence that marketing initiatives can have on consumer behaviour, provided that advertising campaigns are composed and executed effectively (Shimp, 2010; Wiles \& Danielova, 2009; Egan, 2007). The purpose of advertisements is to persuade a person to act or behave in a specific manner (O'Guinn, Allen \& Semenik, 2009). Similarly, social advertising campaigns should ultimately influence the behavioural intent of individuals toward whom prevention campaigns are aimed (Shimp, 2010; Govender, 2009).

Social marketing programmes address various pandemics and anti-social behaviour in order to get people to change destructive behaviours. Examples of social problems addressed include smoking, drug abuse, drunk driving, or unprotected sexual contact leading to the spread of HIV/Aids - activities where many citizens are not acting in line with accepted healthy social conduct. The proliferation of several of these social problems, especially in developing countries such as South Africa, indicates that not enough change is taking place. Thus, in the quest for crucial change, there has been a review of the effectiveness of fear appeals as a means of influencing behaviour. But how can fear appeals be used effectively in a developing country? Many marketers have stayed away from using fear appeals because 
it is difficult to use them effectively (Peng, 2006; LaTour \& Tanner, 2003). Moreover, the effectiveness of fear appeals is not uniform, since other constructs that are connected with fear appeals - especially perceptions of self-efficacy ("I can do this"), response efficacy ("This can be done"), threat ("Something bad will happen unless you act this way"), severity ("You could even die"), and social influence ("Other people act this way") - influence an individual's behaviour (Johnston \& Warkentin, 2010). Other forces as well influence a person's behaviour, such as one's own experience and one's culture. Given the increase in socialissue-related communication, and given populations characterised by a wide variety of different subgroups and their subcultures, social advertising is still all too often targeted at a heterogeneous audience with a standardized message. But standardized messages, at least in some contexts, do not seem to be producing the expected results (Peng, 2006).

A number of previous fear appeal study models (Arthur \& Quester, 2004; Witte, 1992, 1994) were aimed at clarifying the role of fear in establishing the effectiveness of advertising. These studies also examined the moderating role of coping appraisal (i.e., "How possible is it for me to act this way?") in determining consumer response. These studies also assessed perceptions of severity, susceptibility, response efficacy and self-efficacy as related to the fear appeal. The purpose of this paper, however, is to report on a study of the influence of different levels of fear-based advertising appeals pertaining to HIV/Aids on specific population segments in South Africa. This paper aims to inform decision making in terms of the management and support of social marketing campaigns within the South African context. It also presents an empirically-based model of how various constructs work along as antecedents to fear and attitude to influence behavioural intent. Structural equation modeling and partial least squares are used to identify relationships in order to ascertain whether the use of fear increases the likelihood of adopting appropriate safe sexual behaviour pertaining to HIV/Aids prevention.

\section{Defining fear appeals}

Fear appeal literature indicates that fear can be described by mood adjectives, including feeling frightened, anxious, and/or nauseous, and also by ratings of concern or worry, for instance about a negative health outcome like contracting HIV through unprotected sex (LaTour \&Tanner, 2003; LaTour \& Rotfeld, 1997; Henthorne, LaTour \& Nataraajan, 1993; Rogers, 1983). Fear of contracting HIV thus seems to motivate actions, namely changing sexual behaviour, aimed at reducing these unpleasant emotions (Tanner, Hunt \& Eppright, 1991; LaTour \& Zahra, 1989). Fear also relates to risk-taking behaviour, as well as to protective sexual behaviour, which is now often addressed by social marketing efforts (Tudor, 2003). Various other advertising approaches are used, ranging from humor to self-idealization, but which still include the use of fear where an individual is warned that if the current behaviour continues the probability of negative health consequences is high (Belch \& Belch, 2012). Consumer behaviour literature also provides evidence of the influence of emotional reactions (i.e. fear of contracting HIV) on attitude (i.e. believing the probability of negative health consequences), as well as the influence that attitude has on behavioural intent (i.e., changing behaviour to safe sexual behaviour that guarantees protection from contracting HIV) (Shiffman \& Kanuk, 2007; Hawkins, Mothersbaugh \& Best, 2007; Bohner \& Wänke, 2002; Bagozzi, Gurhan-Canli \& Priester, 2002).

\section{Fear appeal models}

Different theories and models developed over the past five decades propose two distinctive approaches to studying how fear relates to persuasion. The first approach centers on outcomes related to acceptance of a message's recommendations, namely changing attitudes, intentions and behaviour in line with the recommendations, therefore assuming a linear relationship between fear intensity and persuasion. The second approach centers on outcomes related to rejection of the message, such as defensive avoidance, reactance and denial, thus assuming a curvilinear relationship between the intensity of fear appeal used and effective change (Barth \& Bengel, 2000; Witte \& Allen, 2000). The present study investigated a non-linear model of how fear appeals relate to other aspects of an advertising appeal.

Various models to improve the effectiveness of fear appeals in advertising have been proposed. Tay, Ozanne \& Santiono (2000) recommend that the utilization of fear appeals should be segment specific and influence different population segments differently. Segmentation may be based on a variety of variables including age, gender, culture and their involvement in the behaviour under investigation, such as smoking, drunk driving or unprotected sexual contact (Quinn et al., 1992; Burnett \& Oliver, 1979 cited in Tay et al., 2000). For example, a drunk-driving campaign aimed at young adults could include higher levels of fear for males versus lower levels of fear for females. Different execution styles, namely, factual information versus 'slice of life,' could also be used for males and females, addressing their specific drinking behaviours (Bakir, 2012).

Individuals need to be encouraged, reinforced, and supported to change their high-risk behaviour into healthy behaviour in order to prevent the spread of HIV/Aids (Fishbein, 2000; Lee \& Green, 1991). Three variables in particular, namely attitude, norms and self-efficacy, are the function of underlying determinants (Fishbein, 2000; Lee \& Green, 1991). These determinants include beliefs about the outcome of behavior, social and normative prescriptions within that population, and specific barriers to these actions. External influences should be included when evaluating these beliefs: cultural background, perceived vulnerability to infection and personality traits may have a mediating influence on attitudes, norms and self-efficacy beliefs (Fishbein, 2000). 


\section{Applying fear appeals to different market segments}

The Extended Parallel Process Model (EPPM) is an expansion of previous fear appeal theoretical approaches (Janis, 1967; Leventhal, 1971; Rogers, 1975; Rogers, 1983; Witte, 1992). According to the EPPM, threat motivates action, and perceived efficacy determines whether the action taken will be either to control the danger (through protective behaviour) or to control the fear (which inhibits protective behaviour). Individuals typically weigh their risk of actually experiencing the threat against actions or coping measures they can take that would minimize or prevent the threat. Message descriptions of a threat focus on the severity of the threat (e.g. "HIV/Aids leads to death") and also on the targeted segments' susceptibility to the threat (e.g. "You're at risk of contracting HIV/Aids because you have unprotected sex") (Witte, 1992, Witte, 1994, Witte, 1998).

Coping measures consists of perceived response efficacy and self-efficacy. Perceived response efficacy refers to an individual's beliefs that a response effectively prevents the threat (e.g., "I believe condoms prevent HIV contraction"), and perceived self-efficacy refers to an individual's belief in his or her ability to perform a recommended response (e.g., "I think that I can use condoms to prevent HIV contraction") (Witte, 1998; Rogers, 1983). If results of a survey indicate high threat and low efficacy, theory indicates that the intervention was failing, because it was promoting fear control responses. Conversely, if the results of a survey indicate high threat and high efficacy, then the intervention was producing the desired actions (Witte \& Allen, 2000). Individual differences however influence one's assessment of threat and efficacy. Individuals evaluate the components of a message relative to their prior experiences, culture, and personality characteristics, which can cause differing perceptions and consequently influence outcomes (Arthur \& Quester, 2004; Witte, 1992).

Growing evidence suggests that well-designed, welltargeted, theory-based behavior change interventions can be effective in reducing the spread of HIV/Aids (Fishbein, 2000). A subsequent study by Arthur and Quester (2004) aimed to clarify the role of fear in establishing the effectiveness of advertising when using fear appeals. Arthur and Quester (2004) also examined the moderating role of coping appraisal in determining consumers' response to fear appeals and whether these processes apply equally to different segments or individual differences of consumers. Culturally sensitive interventions have been found to more effectively create behaviour changes in high-risk populations such as adolescents. This finding implies that interventions which are based not only on sound theoretical knowledge of behaviour change (e.g. social learning theory, the health belief model, and self-efficacy theory), but also take into account cultural beliefs and attitudes, are more likely to succeed (Levinson, Sadigursky \& Erchak, 2004).

\section{Market segmentation approaches}

Since all the marketing mix elements are combined as a strategy to influence a specific target market, Moran (1990) suggested that advertising cannot necessarily address the needs of a multivariate segment and concluded that successful market segmentation should be based on one variable at a time, or two variables at the most. Only then can communication objectives be measured successfully. It is likely that advertisements using specific emotive elements would obtain more attention than a neutral or informative advertisement (Heath, Nairn \& Bottomley, 2009). When advertising processing takes place, three attentive levels are found: active (high attention), passive (low attention), and implicit (no attention). Emotions processed without attention can still be linked to semantic memory and influence behaviour without the respondents' awareness of being influenced. This also implies that the fear emotion could have a similar effect. It is therefore suggested that low attention might be seen as an advantage. A suggestion is that the future of television advertising specifically could be about inserting persuasive emotional ideas into the mind of the consumer. When this strategizing is linked to a brand through creative advertising, effectiveness will increase (Heath, 2011).

Social advertising campaigns concerning issues such as safer sexual behaviour aim to be effective by means of influencing the target market's behavioural patterns and habits. Such campaigns use emotions to create a behavioural response. Behavioural theories such as the Theory of Reasoned Action and Theory of Planned Behaviour are structured around a theoretical sequence of attitude-intention-behaviour (Evans, Jamal \& Foxall, 2006). However, in order for an attitude to be formed, and to be followed by the related behaviour, certain mediating variables are said to stimulate attitude formation and behavioural action. These include prior experience and culture (Schiffman \& Kanuk, 2007).

\section{Culture and racial groups}

The idea of culture (and subculture) as sets of beliefs, values and actions that characterize a certain group of people is well accepted. However, there seem to be clear selfgroupings based on race, and such groupings often seem to follow cultural or subcultural groupings. The present study was done in South Africa, where the idea of race is still present especially in the context of initiatives to empower people that in the past were discriminated against because of their skin colour. Race now seems at times to be a shorthand way of referring more to one's culture. A racial group thus has more of a culture-group meaning. Since the South African government still identify people in racial terms (StatsSA, 2012), the present study use these terms as a proxy for culture.

Marketing communication has to take into account the cultural and economic fabric of society, with different types of people from different racial/culture groups (Lane, King \& 
Russell, 2009). Research on race and marketing communication interventions suggest that racial groups differ in responses to communication, advertising effectiveness and attitudes towards messages (Dines \& Humez, 1995).

Literature presents various definitions in describing what constitutes cultural composition. Culture includes values, which are learned and transmitted through cultural belonging. For the purposes of this study, when referring to 'culture', the researchers refer to the accumulation of all learned beliefs, values and customs that act as a means of directing the behaviour of a consumer who belongs to a particular society or cultural group (Schiffman \& Kanuk, 2007). According to Hawkins et al. (2007), culture directs behaviour. As sexual behaviour and the acceptance of premarital intercourse stem from a culture's pre-set values, it can be assumed that because different cultural groups have different values; sexual behaviour in one cultural group can differ from that of the next. It can be assumed that culture will affect, for example, the age at which individuals become sexually active, as well as with whom and whether protective sexual habits are practiced. In investigating social campaigns and their application in order to result in protective behaviour, culture presents itself as a necessary variable to be considered.

\section{HIVIAIDS communication and fear}

Specific HIV/Aids interventions explored in developing countries include a study by Caldwell \& Kleppe (2010), which investigated the roles of early adopters of HIV/Aids public health innovations. These early adopters, who were people living with HIV/Aids, performed the role of public spokesmodels of HIV/Aids-positive living, but stigmatization, gender roles and poverty, among other factors, made their role difficult to enact. The challenges to social advertising in communicating HIV/Aids messages in terms of message development and delivery from the perspective of the producer of the messages - were explored by Scott and Williams-Smith (2007). Scott and WilliamsSmith (2007) found that successful message development was influenced by stigmatization, conflicting cultural ideals, and resource constraints.

Research shows that about 50 percent of HIV infections in South Africa are transmitted to people before the age of 20, with more than 5.6 million HIV positive people in a country with 50 million people (Avert, 2011, World Health Organisation, 2011). The number of Aids related deaths in South Africa during 2011 was 270 000, with an average life expectancy of 54 years (Avert, 2011). Over 35 million people across the world have died from Aids, and 34 million people were living with HIV at the end of 2011. Sub-Sahara Africa is affected most severely, with one in twenty adults living with HIV, accounting for $69 \%$ of people living with HIV/Aids worldwide (World Health Organisation, 2011).

In South Africa, local and international government efforts have been employed to reduce the spread of this epidemic.
When comparing South African HIV/Aids prevention advertising campaigns to the fear levels and composition of international campaigns, the South African advertisements seem to have very low levels of fear emotion. Yet fear has been found to be an important element for social advertising campaigns (UNAIDS, 2010; Witte, 1998; LaTour \& Rotfeld, 1997; Tanner et al., 1991; Witte, 1992; Beck and Lund, 1981).

The lack of a fear appeal is evident throughout loveLife, South Africa's major multimillion Rand HIV/Aids prevention campaign. In 2011 loveLife had received R125.9m from various government departments, including the Departments of Health, Social Development, and Sport and Recreation. An undisclosed amount was also received from various large corporate sponsors (PMG, 2012). The loveLife prevention campaign follows an informational appeal approach and is an educational campaign that emphasizes condom use and "positive sexuality" (Peng, 2006; Green, 2004, cited in Green \& Witte, 2006). It does not seem that loveLife is producing the expected results, considering the lack of impact on the target audience over a long period of time (Peng, 2006). Based on their strategic priorities for 2012 to 2014, loveLife aims to: deepen the targeting of most at risk populations; generate knowledge about young people and their risk behaviour; and challenge the structural drivers of HIV (PMG, 2012).

HIV/Aids prevention advertisements employed in South Africa do not seem to be tailored to the different cultural needs of South African racial groups. Although sexual behaviour is not solely the result of an individual's cultural background, how, when and why one would satisfy sexual needs can be related to cultural beliefs (Hawkins et al., 2007). Culture must be considered especially in South Africa with its 11 official language groups and its three major racial groups referred to as black (79.2\%), coloured (8.9\%), and white (8.9\%) (StatsSA, 2012).

Figure 1 is a typical advertisement used in the loveLife campaign. One can observe the absence of an appeal to fear, with a more informational appeal approach followed in this advertisement, although fear has been found to be an important element in social advertising campaigns (Witte, 1998; LaTour \& Rotfeld, 1997). Thus a more effective social advertising campaign seems necessary. The study reported here aims to examine how fear appeals work to influence intended behaviour of young-adults within different cultural/racial groups in South Africa.

\section{Methodology of the study}

\section{Overview}

The premise of the study, based on the theoretical foundation discussed in the preceding paragraphs, are the coping responses of respondents, expressed in changes towards particular sources of stimuli as well as their intended behavioural changes when they experience fear brought on by threatening stimuli. Social advertising 
campaigns should ultimately influence the behavioural intent of individuals toward whom prevention campaigns are aimed (Shimp, 2010; Govender, 2009). It seems that standardized messages do not seem to be producing the expected results, especially within specific market segments like the young-adult market (Peng, 2006, Witte, 1998). A number of previous fear appeal study models (Arthur \& Quester, 2004; Witte, 1992, 1994) were aimed at clarifying the role of fear in establishing the effectiveness of advertising. These studies also examined the moderating role of coping appraisal (i.e., "How possible is it for me to act this way?") in determining consumer response. These studies also assessed perceptions of severity, susceptibility, response efficacy and self-efficacy as related to the fear appeal.

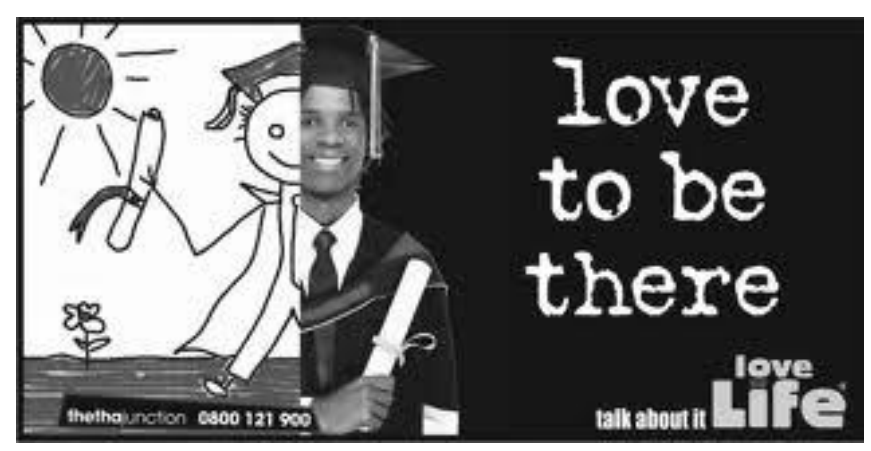

Figure 1: Typical lovelife advertisement

This study will investigate if fear appeals can influence attitude as an antecedent of behavioural intent, and ultimately behavioural change amongst young-adults. Threat appraisal, consisting of severity and susceptibility to the threat posed by HIV/Aids, as well as coping appraisal, consisting of response efficacy and self-efficacy, and the influence on attitude, will be examined as antecedents to fear and attitude respectively (O’Guinn, Allen \& Semenik, 2009).

The model of fear appeal and behavioural intent in this study focuses on the equivalence of the Proposed Revised Protection Motivation model (Arthur \& Quester, 2004) and the Extended Parallel Process Model (Witte, 1992). The model proposes that if a threatening stimulus (fear appeal) maximizes fear experienced by individuals, and the coping response will be effective in eliminating the fear, while the individual is capable of undertaking it, the stimulus will be effective in changing their attitude towards the stimulus and their behavioural intent. The threat-appraisal variables, susceptibility and severity, will therefore indirectly influence behavioural change through the mediating variable fear. The coping appraisal variables, response efficacy and self-efficacy, will have a moderating influence in determining individuals' response to fear appeals.

An experimental study was done to determine responses to three levels of fear appeals regarding HIV/Aids, in both print advertisements and television advertisements, with 360 young adults from different gender and racial groups based on market segments. Responses were analysed to determine the effectiveness of these advertisements in changing behavioural intent and to compare results. Data was collected by means of a survey and responses were analysed according to key constructs derived from fear appeal literature. A model was identified, and then applied to the specific market segments (Arthur \& Quester, 2004; Witte, 1998).

To obtain relevant fear appeals, a qualitative study preceded the experimental study. The qualitative study began with a search for print and television advertisements that used a fear appeal, from which 19 were selected. These 19 were tested with 40 respondents in focus groups from the three main racial groups in the country. Their in-depth responses were analysed, and in the end, six advertisements (three print and three television) were chosen to be used as experimental stimuli.

\section{Stimuli}

Ten television commercials and nine print advertisements were used for the qualitative study. First, however, a selection of advertisements was taken from various sources, including fifty different websites using a key word search for 'HIV/Aids advertising'. All the main South African and international campaigns for HIV/Aids prevention were investigated. Experts in the field of marketing research and the advertising industry were consulted to ensure that the selected advertisements were appropriate and would be understood by the target audience, and to judge the advertisements for face validity. Each advertisement was rated according to the level of fear appeal perceived. Six advertisements - representing low, medium and high fear appeals for print and television - were selected based on the qualitative research. It is important to note that advertisements were selected based on the fear level evoked and not on the content or execution of the various advertisements, as fear level was crucial to the purpose of the experimental part of the study.

The three television advertisements used as experimental stimuli included:, “Tshepo \& Busi” - a loveLife campaign with the message explaining the way the HIV virus spreads from one person to the next via unprotected sex - as a low fear stimulus; "Dumpster" - a message giving hope, that you are not alone with HIV/Aids, and that, if people stand together, HIV can be prevented - as a medium fear stimulus; and "Tsunami" - comparing the devastation of a tsunami to the spreading of HIV/Aids as a high fear stimulus. The three print advertisements used as experimental stimuli are shown below in Figures 2 to 4. The low fear advertisement, Figure 2, "He knows, she knows" promotes getting an HIV test and knowing your status. The medium fear advertisement, Figure 3, depicts a paramedic who knows his HIV status and is therefore in control of his health and lifestyle. Figure 4, the high fear advertisement, depicts a tombstone with two sexual partners and the inscription "Aids is still around." 


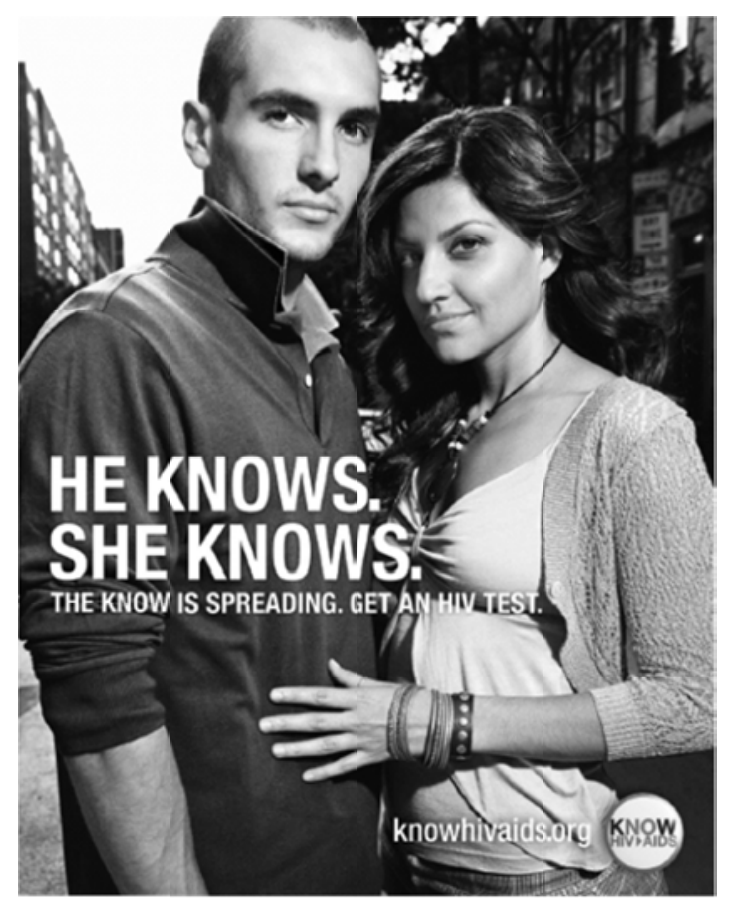

Figure 2: Low fear print advertisement

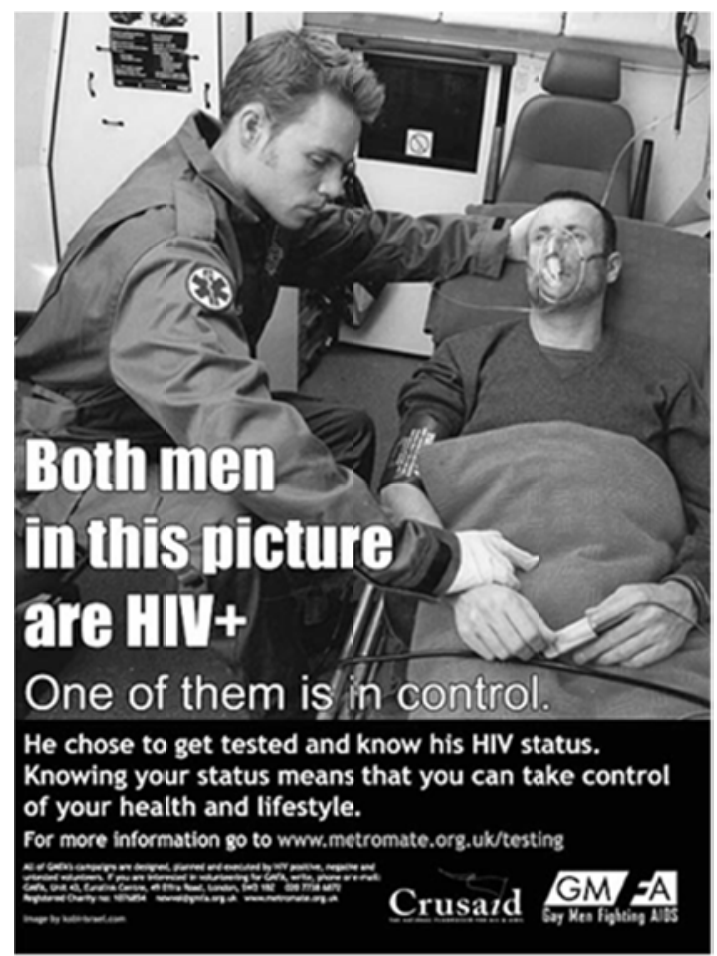

Figure 3: Medium fear print advertisement

\section{Sampling and subjects}

Young adults between the ages of 18 and 24 years, from the three largest racial groups in South Africa, were identified as the research population. Quota sampling was used to draw respondents from this population, and these respondents were invited to participate in the research via an independent fieldwork research company. These respondents represented educated, middle to upper income groups who had access to television and print media and advertising. The final sample of 360 respondents included an equal male and female split, with 120 respondents per racial group, namely black, white and coloured.

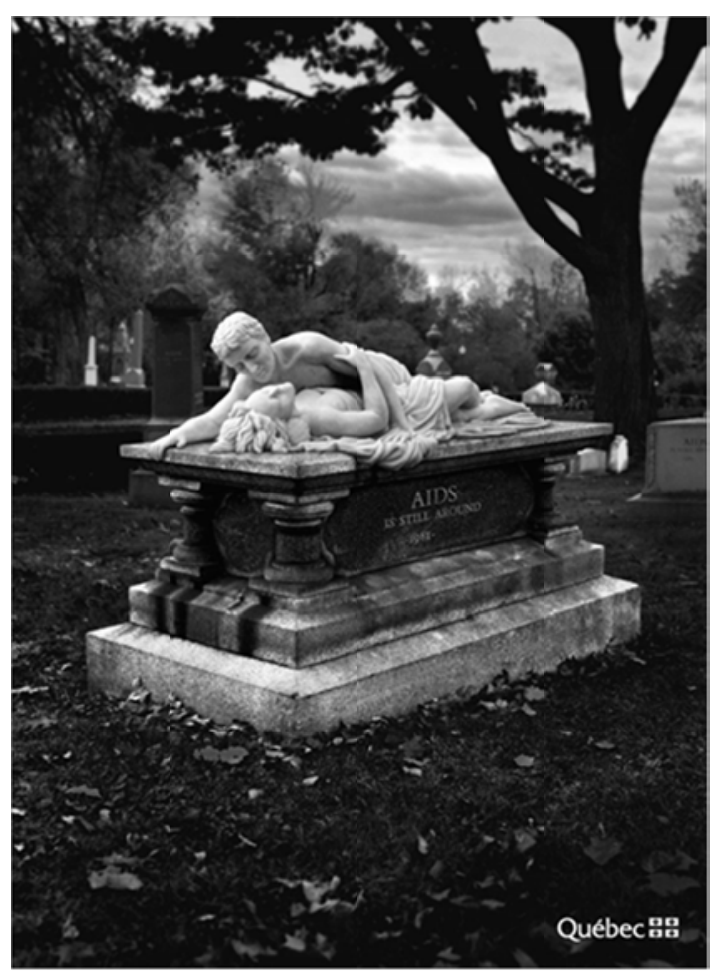

Figure 4: High fear print advertisement

Data collection

Respondents were requested to complete a questionnaire with questions based on a risk behaviour diagnosis Likert scale prior to any intervention and the same behaviour scale post-intervention, similar to a procedure used by Witte (1998). Fear arousal was measured post-intervention by having respondents rate mood adjectives. Attitude towards the various fear appeal advertisements was also measured post-intervention by using summed scales (LaTour \& Tanner, 2003; LaTour \& Rotfeld, 1997). Severity and Susceptibility measures includled the severity of the threat of HIV/Aids ("I believe that HIV" infection has serious negative consequences") and susceptibility to the threat of HIV/Aids ("I am at risk of contracting HIV") (Witte, 1992). Efficacy measurements included response efficacy (effectiveness of suggested response, e.g., "Using condoms is effective in preventing HIV infection") and self-efficacy (ability to carry out the suggested response, e.g., "I am able to use condoms to prevent getting HIV infection"). The experimental intervention was conducted by handing out print advertisements representing low, medium and high fear; this was followed by television advertisements which were shown on a screen in the venue from low to high fear. 


\section{Analysis}

Structural Equation Modeling (SEM) measures a set of dependent relationships simultaneously and was therefore appropriate for this study (Malhotra \& Birks, 2007; Hair, Black, Babin, Anderson \& Tatham, 2006). The proposed model contains a path diagram that depicts the relationships between constructs. LISREL was used to determine the dependence relationships in the model. Differences amongst race and gender groups were investigated with the use of Partial Least Squares of Statistica software.

For the SEM analysis an estimated covariance matrix was calculated to assess the degree of fit to the observed covariance matrix. Goodness-of-fit was indicated as the degree to which the actual correlations (or the covariance matrix used as input) were predicted by the model. In this instance the model produced an estimated covariance matrix that was within sampling variation of the observed covariance matrix and therefore illustrates a good fit (Hair et al., 2006). Table 1 illustrates the goodness-of-fit indices for the model.

The RMSEA was 0.057 which indicated good fit compared to the acceptable 0.05 to 0.08 range (Hair et al., 2006). The Normed Fit Index (NFI) and the Comparative Fit Index (CFI) are above the 0.9 level and indicate an acceptable goodness-of-fit. The Incremental Fit Index (IFI) also resulted in a value greater than the acceptable 0.9 level (Hair et al., 2006).

Table 1: Goodness-of-fit indices for the SEM Model

\begin{tabular}{l|l}
\hline Goodness-of-fit indices & Values \\
\hline Degrees of Freedom & 483 \\
\hline Satorra-Bentler Scaled Chi-Square & $687,5(\mathrm{p}=0.00)$ \\
\hline $\begin{array}{l}\text { Root Mean Square Error of Approximation } \\
\text { (RMSEA) }\end{array}$ & 0.057 \\
\hline Normed Fit Index (NFI) & 0.93 \\
\hline Comparative Fit Index (CFI) & 0.96 \\
\hline Incremental Fit Index (IFI) & 0.94 \\
\hline Goodness of Fit Index (GFI) & 0.98 \\
\hline
\end{tabular}

\section{Fear appeal and behavioural intent}

Analysis was done first on all 360 respondents, then on segments based on gender, and finally on segments based on culture/racial groupings.

\section{Fear appeal and behavioural intent: All respondents}

Figure 5 illustrates the results obtained from SEM analysis for all respondents. Based on the SEM analysis, interpretations were made of each relationship in the model. The probability that estimates were significant (i.e., not equal to zero) were used to make estimates of the values of constructs in the model (Hair et al., 2006).

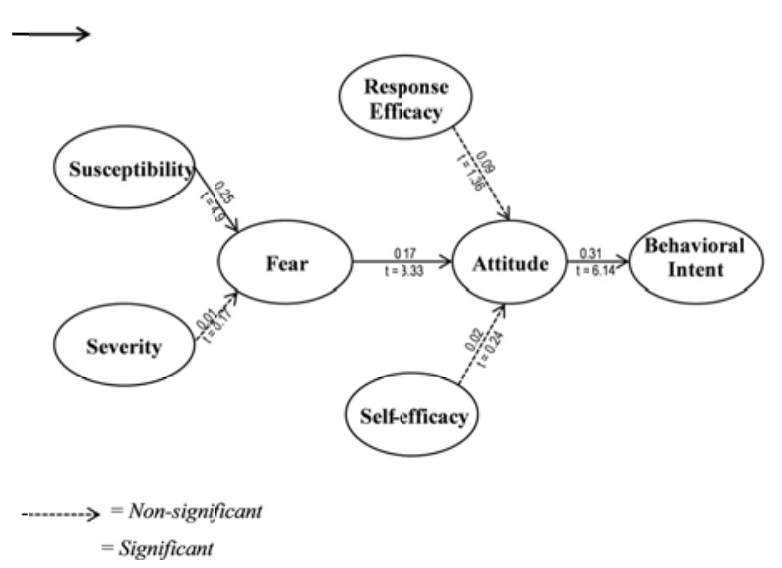

Figure 5: Structural equation model of fear appeal and

The estimated path coefficients of the first two relationships, namely susceptibility and severity, illustrated that susceptibility had the greatest influence on fear, and severity was insignificant. This was in line with the findings of Arthur and Quester's (2004) study which also reported a causal relationship between susceptibility and fear, but not between severity and fear. They concluded that fear is an emotional response to a stimulus and many of the antecedents may be more affective than cognitive. The findings of this study partially supports Witte's (1992; 1998) explanation that an individual evaluates the perceived threat of the danger, and if the appraisal of threat results in a moderate to high perceived threat, then fear is caused. However, the findings of this study indicate only that the susceptibility construct of threat influences the relationship with fear and not the severity construct. A possible explanation could be that severity is something outside the control of an individual.

Both response efficacy and self-efficacy indicated insignificant relationships with attitude. The study by Arthur and Quester (2004) illustrates similar results stating that response efficacy and self-efficacy do not necessarily act as moderating variables in the fear-behavioural-intent relationship. They also confirm fear as the primary driver for change in behavioural intent. Witte (1998) on the contrary states that an individual that experiences a threat is motivated to begin a second appraisal, which is an assessment of the efficacy of the suggested response. Thus, according to Witte (1998), when perceived threat and perceived efficacy are high, it stimulates adaptive actions such as attitude, intention, or behaviour changes that control the danger. However no support for this was found in this study.

Other positive causal relationships included fear to attitude and attitude to behavioural intent. This is in line with theory indicating that the higher a fear appeal, the more effectively it influences attitude and fïnally behaviour (LaTour \& Tanner, 2003; Snipes, LaTour \& Bliss, 1999; Donovan, Jalleh \& Henley, 1999; LaTour \& Rotfeld, 1997; LaTour, Snipes \& Bliss, 1996; Henthorne, LaTour \& Nataraajan, 1993). Arthur and Quester (2004) confirm this finding 
stating that susceptibility influences behavioural intent indirectly through the mediating variable of fear.

\section{Fear appeal and behavioural intent: Gender}

The study also investigated the relationships in the model pertaining to male and female respondents. The individual path coefficients in the PLS structural model can be interpreted as standardized beta coefficients of ordinary least squares regressions. Paths coefficients that are nonsignificant or have signs contrary to the hypothesized direction do not support a prior hypothesis, whereas significant paths showing the hypothesized direction empirically support the proposed causal relationship (Henseler, Ringle \& Sinkovics, 2009). Table 2 below illustrates the results obtained from the PLS analysis for the male (180) and female (180) respondents separately.

Table 2: PLS path analysis: Male versus female

\begin{tabular}{l|l|l|l|l}
\multicolumn{2}{l|}{} & \multicolumn{2}{l|}{ Female } & \multicolumn{2}{l}{ Male } \\
\hline Path & $\begin{array}{l}\text { Path } \\
\text { coefficient }\end{array}$ & Significance & $\begin{array}{l}\text { Path } \\
\text { coefficient }\end{array}$ & Significance \\
\hline $\begin{array}{l}\text { Attitude -> } \\
\text { Behavioural intent }\end{array}$ & 0.32 & $\mathrm{~s}$ & 0.37 & $\mathrm{~s}$ \\
\hline Fear -> Attitude & 0.22 & $\mathrm{~s}$ & 0.22 & $\mathrm{~s}$ \\
\hline $\begin{array}{l}\text { Response efficacy-> } \\
\text { Attitude }\end{array}$ & 0.10 & $\mathrm{n} \mathrm{s}$ & 0.18 & $\mathrm{n} \mathrm{s}$ \\
\hline $\begin{array}{l}\text { Self-efficacy -> } \\
\text { Attitude }\end{array}$ & 0.15 & $\mathrm{n} \mathrm{s}$ & 0.09 & $\mathrm{n} \mathrm{s}$ \\
\hline Severity -> Fear & 0.17 & $\mathrm{n} \mathrm{s}$ & -0.19 & $\mathrm{n} \mathrm{s}$ \\
\hline $\begin{array}{l}\text { Susceptibility -> } \\
\text { Fear }\end{array}$ & 0.35 & $\mathrm{~s}$ & 0.24 & $\mathrm{~s}$ \\
\hline
\end{tabular}

The results confirmed a causal relationship between susceptibility and fear, with female respondents experiencing a stronger relationship. Severity was insignificant and had an insignificant effect as an antecedent to fear for both males and females. Fear was a driver for change in attitude for both males and females. Response efficacy and self-efficacy indicated insignificant relationships with attitude and it can be concluded that these constructs do not stimulate adaptive action such as attitude or behaviour change.

Both groups of respondents showed that attitude affected their behavioural intent significantly. Female and male respondents deemed themselves incapable of changing their attitude as both self-efficacy and response efficacy indicated an insignificant relationship with attitude for both groups, this underlines their belief in their inability to carry out the suggested response.

Fear appeal and behavioural intent: Culture/racial groupings

Interpretations were also made of each relationship in the model specifically pertaining to the different culture/racial groups in the sample, namely black, coloured, and white. Table 3 below illustrates the results obtained from the PLS analysis for the 120 respondents per culture/racial groups.
Table 3: PLS path analysis: Culture/racial groups

\begin{tabular}{|c|c|c|c|c|c|c|}
\hline \multirow[b]{2}{*}{ Е } & \multicolumn{2}{|c|}{ 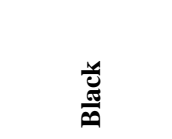 } & \multicolumn{2}{|c|}{ 몰 } & \multicolumn{2}{|c|}{ 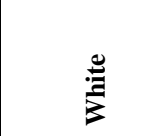 } \\
\hline & = & : & = & 氙 & = & : \\
\hline $\begin{array}{l}\text { Attitude -> } \\
\text { Behavioural } \\
\text { intent }\end{array}$ & 0.32 & $\mathrm{~S}$ & 0.34 & $\mathrm{~s}$ & 0.35 & $\mathrm{~s}$ \\
\hline $\begin{array}{ll}\text { Fear } & -> \\
\text { Attitude } & \end{array}$ & 0.22 & $\mathrm{n} \mathrm{s}$ & 0.22 & $\mathrm{~ns}$ & 0.18 & $\mathrm{~s}$ \\
\hline $\begin{array}{l}\text { Response } \\
\text { efficacy } \quad-> \\
\text { Attitude }\end{array}$ & 0.17 & $\mathrm{n} \mathrm{s}$ & 0.11 & $\mathrm{n} \mathrm{s}$ & 0.20 & $\mathrm{~ns}$ \\
\hline $\begin{array}{l}\text { Self-efficacy } \\
\text {-> Attitude }\end{array}$ & 0.17 & $\mathrm{n} \mathrm{s}$ & 0.20 & $\mathrm{n} \mathrm{s}$ & 0.09 & $\mathrm{~ns}$ \\
\hline $\begin{array}{ll}\text { Severity } \quad-> \\
\text { Fear }\end{array}$ & -0.13 & $\mathrm{~ns}$ & 0.31 & $\mathrm{n} \mathrm{s}$ & 0.15 & $\mathrm{~ns}$ \\
\hline $\begin{array}{l}\text { Susceptibility } \\
\text {-> Fear }\end{array}$ & 0.32 & $\mathrm{~S}$ & 0.29 & $\mathrm{~s}$ & 0.33 & $\mathrm{~s}$ \\
\hline
\end{tabular}

- Black racial group: The black racial group felt susceptible to HIV/Aids, with a significant relationship between susceptibility and fear. This was in line with the findings of Arthur and Quester's (2004) study, and partially supports Witte's studies (1992, 1998). Severity was insignificant as an antecedent to fear. Also, response efficacy and self-efficacy indicated insignificant relationships with attitude. This group differed from the white group in that, although fear was present, this had no significant effect on their attitudes as an antecedent to behaviour change. It is likely that this largest racial group (79.2\%) is more exposed to the prevalence of HIV/Aids in their communities due to historical factors.

- Coloured racial group: A significant relationship between susceptibility and fear existed, as per the study of Arthur and Quester (2004), with severity being insignificant as an antecedent to fear. Fear was nonsignificant as a precursor to change attitudes, and response efficacy and self-efficacy also indicated insignificant relationships with attitude. Attitude had a significant effect on behavioural intent. This is in conflict with reported theory (LaTour and Tanner, 2003; Snipes, LaTour and Bliss, 1999) indicating that the higher a fear appeal, the more effectively it influences attitude and finally behaviour.

- White racial group: Similar to the other racial groups, a significant relationship between susceptibility and fear was found, with severity being insignificant as an antecedent to fear, as per the study by Arthur and 
Quester (2004). Fear was a driver for change in attitude, as per the studies of LaTour and Tanner (2003) and Snipes, LaTour and Bliss (1999), but response efficacy and self-efficacy indicated insignificant relationships with attitude. It can be concluded that these constructs do not stimulate adaptive action such as attitude or behaviour change. Attitude had a significant relationship with behavioural intent.

\section{Conclusions and implications}

The main objective of this research study was to measure the influence of fear-based advertising appeals pertaining to HIV/Aids on specific market segments in order to inform decision-making in managing and supporting social marketing campaigns within the South African context. Fear appeals were measured in terms of the impact on behavioural intent and of whether the use of fear increases the likelihood of adopting appropriate behaviour. SEM and PLS were used to investigate the relationships between fear, attitude towards the advertisements, severity, susceptibility and efficacy to determine the influence of fear appeals on behavioural intent within differing market segments based on gender and culture/race.

Overall, a causal relationship between susceptibility and fear confirmed that susceptibility had the greatest impact on fear. On the contrary, severity was insignificant and had no effect as an antecedent to fear. This implies that the total group of respondents feels susceptible to the threat of contracting HIV/Aids and susceptibility influences their fear experienced. However, although HIV/Aids are severe, severity does not influence their fear experienced or ultimately their behavioural intent. A possible explanation for severity not influencing their fear experienced could be that young South African adults' senses have become numbed by the many reports on HIV/Aids or even the presence of HIV/Aids. They live in a country where more than ten percent of the population is HIV positive and 50 percent of HIV infections are transmitted to people before the age of 20. Young-adults thus rather evaluate the perceived threat of the danger associated with contracting HIV/Aids, and if this appraisal of their susceptibility results in moderate to high perceived threat, then fear is caused. Response efficacy and self-efficacy indicated insignificant relationships with attitude and it can be concluded that these constructs do not stimulate adaptive action such as attitude or behaviour change (i.e. using condoms) and do not necessarily act as moderating variables in the fearbehavioural-intent relationship for this particular youngadult group.

According to the findings of this study, fear is only a driver for change in attitude, but not behavioural intent, as per the fear appeal theory where outcomes relate to acceptance of the recommendations of a message. When individuals are confronted with a threatening stimuli and experience fear, they try to eliminate the unpleasant feeling by intending to perform a certain coping response to reduce the threat of contracting HIV/Aids. Perhaps a higher fear appeal or different execution would more effectively influence attitude and finally behaviour.

\section{HIVIAIDS fear appeals and segmentation}

When considering the results of this study the relationships of fear appeals with attitude is mixed in respect of the different segments such as gender and racial groupings. For both males and females, susceptibility influences their levels of fear experienced, and ultimately their attitude towards HIV/Aids fear appeal advertising and HIV/Aids. It is however not that simple to alter behaviour amongst race groups as some respondents know about the danger of contracting HIV, but this does not threaten or motivate them to change their attitude to sexual behaviour. It is possible that the fear appeals offered in the advertising content were not sufficiently scary or deemed as a threat for some groups to adapt their attitude in line with recommendations by the advertisements. It is also possible that they believe they cannot implement suggested behaviour based on their circumstances and beliefs about sex. The black and coloured racial groups' reaction differed in terms of their reaction to fear appeal advertisements, since they felt susceptible to HIV/Aids and fear levels increased, but their attitudes were not influenced. Perhaps the high prevalence of HIV/Aids in their direct communities have desensitised them to the reality and severity of HIV/Aids.

This supports the importance of a segmented approach to HIV/Aids social campaigns, where separate message content will have to be developed and tested for individual segments, to ensure that the message alters their attitude and ultimately their sexual behaviour.

\section{Future HIVIAIDS advertising development}

Social advertising should influence human behaviour for societal benefit, and by supporting social advertising solutions, businesses play a positive part in society. There is no concrete evidence from this study that fear appeals at the levels tested influenced sexual behaviour. This has specific consequences for NPO's in how they plan and manage social advertising campaigns, as well as for government and corporate businesses who invest in and sponsor social advertising campaigns. A key issue of this study concerns the overall implications of the outcomes for future social advertising development by NPO's and when these initiatives should be sponsored by corporates. Primary funding by government and corporate sponsors should be reviewed in lieu of the success of current social advertising initiatives to prevent HIV/Aids. Corporate donations for a non-profit cause are a way of increasing the visibility and success rate of the social cause; and affiliation with a social cause influences the image of the business.

Based on the results of this study, future HIV/Aids social advertising campaigns targeted at young-adults should revisit fear impact levels and severity, and possibly even consider a shock approach, given the reality of HIV/Aids prevalence in South Africa. Message executions that focus 
on the severity of the threat of HIV/AIDS (i.e. "HIV/Aids leads to death") and also on the targeted segments' susceptibility to the threat (i.e. "You're at risk of contracting HIV/Aids because you have unprotected sex") could have a stronger impact on behaviour change. Susceptibility can be enhanced through messages that convey how easy it is for young people to become infected with HIV, as well as demonstrating the debilitating effects of HIV/Aids. Based on some studies (Witte, 1998, 1992), high threat and high efficacy messages deliver the best results and could be developed successfully if different advertising execution styles are considered.

This hopefully will ensure that young people experience a relevant fear that will drive them to change the way they think about HIV/Aids. If this approach is followed, the campaign could ultimately influence young-adults to modify their sexual behaviour to safe sexual behaviour. The differing responses for the individual segments must however be taken into account, specifically the reactions of males and female, and also the different racial groups. This stresses the importance of a segmentation approach to HIV/Aids social marketing efforts, specifically to influence sexual behaviour of individual groups, to restrain the debilitating effect of this disease.

\section{Limitations}

A limitation of this study is that processing and responses to advertising appeals do not always occur immediately after exposure to an advertisement intervention, referred to as the "delayed effect." This study was conducted in an experimental laboratory setting and therefore did not measure this effect over time. Thus there could be stronger effects, which were not observed right away, as in the current study. Areas for future research include replication studies based on the proposed model to measure fear appeal effectiveness on other samples in different settings. Higher levels of fear appeals (even at the "shock" level) can possibly be a motivator if accompanied by high threat and high efficacy messages, to improve knowledge and to influence attitudes about HIV/Aids, and ultimately sexual behaviour. Further research, with specific creative execution styles (i.e. slice-of-life) and content that offers solutions, and possibly with heightened severity and susceptibility messages, should be developed and tested among this target group of young adults to find optimum message content that will influence them to alter high-risk sexual behaviour.

\section{References}

Arthur, D. \& Quester, P. 2004. 'Who's afraid of that ad? Applying segmentation to the Protection Motivation Model', Psychology \& Marketing, 21(9): 671-696.

AVERT. 2011. The South African national HIV survey. [online] URL: http://www.avert.org/safricastats.html.
Bagozzi, R.P., Gurhan-Canli, Z. \& Priester, J.R. 2002. The social psychology of consumer behavior. Great Britain: St Edmundsbury Press Ltd.

Bakir, A. 2012. 'A cross-national analysis of advertisement content', Journal of International Consumer Marketing, 24(3): 185-190.

Barth, J. \& Bengel, J. 2000. Prevention through fear? The state of fear appeal research. [online] URL: http//www.juergen-bart.de/en/wp-content/uploads/ 2007/03/preventionthrough throughfear.pdf.

Beck, K.H. \& Lund, A.K. 1981. 'The effects of health threat seriousness and personal efficacy upon intentions and behavior', Journal of Applied Social Psychology, 11(5): 401-415.

Belch, G.E. \& Belch, M.A. 2012. Advertising and promotion: An integrated marketing communications perspective. 9th Edition. New York: McGraw-Hill/Irwin.

Bohner, G. \& Wänke, M. 2002. Attitudes and attitude change. USA: Taylor \& Francis Inc.

Caldwell, M. \& Kleppe, I. 2010. 'Early adopters in the diffusion of an HIV/Aids public health innovation in a developing country', Advances in Consumer Research, 37: 1-22.

Dines, G. \& Humez, J.M. 1995. Gender, race and class in media: a text-reader. London: SAGE Publications.

Donovan, R.J., Jalleh, G. \& Henley, N. 1999. 'Executing effective road safety advertising: Are big production budgets necessary?', Accident Analysis and Prevention, 31: 243 252.

Egan, J. 2007. Marketing Communications. London: Thomson Learning.

Evans, M., Jamal, A. \& Foxall, G. 2006. Consumer behavior. England: John Wiley \& Sons Ltd.

Fishbein, M. 2000. 'The role of theory in HIV prevention', AIDS Care, 12(3): 77-278.

Govender, S. 2009. Where half of the new moms have HIV. [online] URL: http://www.aegis.org/news/suntimes/ 2009/ST091109.html.

Green, C. \& Witte, K. 2006. 'Can fear arousal in public health campaigns contribute to the decline of HIV prevalence?', Journal of Health Communication, 11: 245259.

Hair, J.F., Black, W.C., Babin, B.J., Anderson, R.E. \& Tatham, R.L. 2006. Multivariate data analysis. 6th Edition. New Jersey: Pearson Prentice Hall. 
Hawkins, D.I., Mothersbaugh, D.L. \& Best, R.J. 2007. Consumer behavior: Building marketing strategy. 10th Edition. New York: McGraw-Hill/Irwin.

Heath, G.H., Nairn, A.C. \& Bottomley, P.A. 2009. 'How effective is creativity? Emotive content in TV advertising does not increase attention', Journal of Advertising Research, December: 450-463.

Heath, R.G. 2011. 'The secret of television's success: Emotional content or rational information? After fifty years the debate continues', Journal of Advertising Research, March Supplement: 112-123.

Henseler, J.H., Ringle, C.M. \& Sinkovics, RR. 2009. 'The use of partial least squares path modelling in international marketing', Advances in International Marketing, 20: 277319.

Henthorne, T.L., LaTour, M.S. \& Nataraajan, R. 1993. 'Fear appeals in print advertising: An analysis of arousal and ad response', Journal of Advertising, 22(2): 59-68.

Janis, I.L. 1967. Effects of fear arousal on attitude change: recent developments in theory and experimental research. In Berkowitz, L. (Ed.). Advances in experimental social psychology. Third Edition. New York: Academic Press.

Johnston, A.C. \& Warkentin, M. 2010 . 'Fear appeals and information security behaviors: An empirical study', MIS Quarterly, 34(3): 549-A4.

Lane, W.R., King, K.W. \& Russell, J.T. 2009. Kleppner's advertising procedure. 17th Edition. New Jersey: Pearson Prentice Hall.

LaTour, M. \& Zahra, S. 1988. 'Fear appeals as advertising strategy: should they be used?', Journal of Services Marketing, 2(4): 5-14.

LaTour, M.S. \& Rotfeld, H.J. 1997. 'There are threats and (maybe) fear-caused arousal: Theory and confusions of appeals to fear and fear arousal itself', Journal of Advertising, 26(3): 45-59.

LaTour, M.S. \& Tanner, J.F. 2003. 'Radon: Appealing to our fears’, Psychology \& Marketing, 20(5): 377-394.

LaTour, M.S., Snipes, R.L. \& Bliss, S.J. 1996. 'Don’t be afraid to use fear appeals: An experimental study', Journal of Advertising Research, 4: 59-67.

Lee, C. \& Green, R.T. 1991. 'Cross-cultural examination of the Fishbein behavioral intentions model', Journal of International Business Studies, 22(2): 289-305.

Leventhal, H. 1971. 'Fear appeals and persuasion: the differentiation of a motivational construct', American Journal of Public Health, 61(6): 1208-1224.
Levinson, R.A., Sadigursky, C. \& Erchak, G.M. 2004. 'The impact of cultural context on Brazilian adolescents sexual practices', Adolescence, 39(154): 203-227.

Moran, W.T. 1990. 'Brand presence and the perceptual frame’, Journal of Advertising Research, 10: 9-16.

O’Guinn, T.C., Allen, C.T. \& Semenik, R.J. 2009. Advertising \& integrated brand promotion. Fifth Edition. USA: South-Western Cengage Learning.

Peng, T., 2006. South Africa: loveLife faces up to funding cuts and critics. [online] URL: http://allafrica.com/ stories/html.

PMG, 2012. Parliamentary monitoring group: LoveLife 2011/2012 Annual report [online] URL: http://www.pmg.org.za/report/20121120-lovelife-201112annual-report.

Rogers, R.W. 1983. Cognitive and physiological processes in fear appeals and attitude change: A revised theory of protection motivation. In Cacioppo, J. \& Petty, R. (Eds.). Social Psychophysiology. New York: Guilford.

Rogers, RW. 1975. 'A protection motivation theory of fear appeals and attitude change', Journal of Psychology, 91: 93114.

Rotfeld, H.J. 2000. 'The textbook effect: conventional wisdom, myth and error in marketing', Journal of Marketing, 64(2): 122-127.

Schiffman, L.G. \& Kanuk, L.L. 2007. Consumer behavior. 9th Edition. New Jersey: Pearson Prentice Hall.

Scott, A.D. \& Williams-Smith, S.A. 2007. 'The director's cut: exploring cultural implications in HIV/Aids communication from the producer's perspective', Advances in Consumer Research, 34: 475-480.

Shimp, T.A. 2010. Integrated marketing communication in advertising and promotion. 8th Edition. South-Western: Cengage Learning.

Snipes, R. L., LaTour, M. S., \& Bliss, S. J. 1999. 'A model of the effects of self efficacy on the perceived ethicality and performance of fear appeals in advertising', Journal of Business Ethics, 19: 273-285.

StatsSA. 2012. South African census report, 2011. [online] URL: http://www.statssa.gov.za/Publications/P03014/ P030142011.pdf.

Tanner, J.F., Hunt, J.B. \& Eppright, D.R. 1991. 'The Protection Motivation Model: A normative model of fear appeals', Journal of Marketing, 55(3): 36-45. 
Tay, R., Ozanne, L. \& Santiono, J. 2000. 'Advertising and road safety: a segmentation approach. ANZMAC 2000, Visionary Marketing for the $21^{\text {st }}$ Century: Facing the Challenges, 1248-1251.

Tudor, A. 2003. 'A (macro) sociology of fear?', The Sociological Review, 51: 238-256.

UNAIDS. 2010. Country progress report on the declaration of commitment on HIV/Aids, 2010. Republic of South Africa. South Africa. [online] URL: http://data.unaids.org/ pub/report /2010/south africa_2010_country_progress_ report_en.pdf.

Wiles, M.A. \& Danielova, A. 2009. 'The worth of product placement in successful films: An event study analysis', Journal of Marketing, 73: 44-63.

Will, K. E., Sabo, C.S. \& Porter, B.E. 2009. 'Evaluation of the boost'em in the back seat program: Using fear and efficacy to increase booster seat use', Accident Analysis and Prevention, 41(1): 57-65.

Witte K. 1998. Theory-based interventions and evaluation of outreach efforts. Seattle, WA: National network of libraries of medicine, Pacific Northwest region. [online] URL: http://www.nnlm.nlm.nih.gov/pnr/eval/witte.html.

Witte, K and Allen, M. 2000. 'A meta-analysis of fear appeals: Implications for effective public health campaigns', Health Education and Behavior, 27(5): 591-615.

Witte, K. 1992. 'Putting fear back into fear appeals: The Extended Parallel Process Model', Communication monographs, 59: 329-349.

Witte, K. 1994. 'Fear control and danger control: A test of the Extended Parallel Process Model (EPPM)', Communication Monographs, 61: 113-134.

World Health Organisation. 2011. Global health observatory. [online] URL: www.who.int/gho/hiv/en.html. 